\title{
Temperature and pressure effect on the HMX/Graphene mixture system thermal decomposition via ReaxFF molecular dynamic simulation
}

Li zhang ( $\square$ zhangli392956443@163.com)

shanxi police college https://orcid.org/0000-0003-3527-9956

Research Article

Keywords: graphene, thermal decomposition, crystal plane, anisotropy, absorption

Posted Date: January 31st, 2022

DOl: https://doi.org/10.21203/rs.3.rs-1279182/v1

License: @ (i) This work is licensed under a Creative Commons Attribution 4.0 International License. Read Full License 


\section{Abstract}

Study the detail mechanisms of energetic materials thermal decomposition process at high temperature, is helpful to understand the detail reaction information and mechanism, which are foundation for understanding reactivity of energetic materials, design of mixed explosives and safety. In this work, new model and method effect of temperature and pressure for graphene (Gr) based HMX crystal were determined by ReaxFF molecular dynamic simulation. The thermal decomposition process, HMX molecules absorption on Gr surface of perfect HMX crystal, different direction crystal planes and HMX/Gr mixed models were studied at high temperature and pressure. The different configurations of HMX molecules adsorbed on graphene surface in the mixed system were confirmed by theoretical calculation method. We observed 3, 5 and $3 \mathrm{HMX}$ configurations absorption on the graphene in the (001)/Gr, (010)/Gr and (100)/Gr range from normal pressure to $31 \mathrm{GPa}$, respectively. The time-dependent curves of fragments evolution, intermediates and pyrolysis products were analyzed. The results show that the rate constants of HMX molecules during thermal decomposition process can be significantly affect by adding graphene with HMX crystal. Gr is the most obvious inhibition effect on the thermal decomposition reaction of (010) surface of HMX/Gr, which indicates that graphene has a coupling between the temperature and thermal anisotropy effect, because of the $\mathrm{NO}_{2}$ functional groups steric hindrance and the interaction between graphene and $\mathrm{HMX}$ molecules. Gr also affects the initial reaction pathways of homolytic cleavage of $\mathrm{N}^{-\mathrm{NO}_{2}}$ bond forming nitro radical and $\mathrm{HONO}$ through the $\mathrm{C}=\mathrm{O}, \mathrm{C}-\mathrm{OH}$ and $\mathrm{C}-\mathrm{OC}$ bonds formation on graphene surface.

\section{Introduction}

Energy materials (EMs) like explosives, pyrotechnics, and propellants play an important role in many fields, etc. aeronautics, and defense industry ${ }^{[1]}$. Because of the high density, energy and tension, EMs are widely used applications ranging from engineering blasting, automobile air bags, oil exploitation to weapon design and rocket propellants preparation ${ }^{[2]}$. Unfortunately, the pure EMs have very high sensitivity, and should be prepared to mixed components by adding some binder, additive, desensitizer, which will be improving the thermal decomposition mechanism, tensile mechanical property and sensitivity. Considering numerous excellent properties of graphene $(\mathrm{Gr})^{[3]}$, such as large specific surface area, high thermal conductivity, and strong conductivity, the family of graphene-based materials (GBMs), such as Gr, graphene oxide (GO) and reduced graphene oxide ( $\mathrm{GGO}$ ) have become a focus in the application of EMs/GBMs

[4]. Recently, GBMs are proposed for additive and desensitizer and are expected to replace the graphite and other compounds in the TATB based ${ }^{[5]}$ and CL-20 based $^{[6-7]}$ plastic-bonded explosive (PBX).

These studies ${ }^{[6-7]}$ have been sought to reveal the reduce mechanical sensitivity and thermal stability reasons when GBMs adding to CL-20 crystal. The results showed that high specific surface areas of graphene and its derivatives make GBMs have large buffer space when the mixture of EMs/GBMs encounter mechanical shock and impact stimulation. The thermal decomposition process was also studied at low temperatures. Due to the good thermal conductivity of graphene, the heat flow will be transferred from graphene to the PBX surface quickly, resulting in the decomposition of PBX ahead of time and reducing its thermal stability; while the rich oxygen-containing functional groups on the surface of $\mathrm{GO}$ will first decompose and release $\mathrm{OH}$ radicals under high temperature, and transfer part of the heat flow to PBX, which also leads to PBX decomposition ahead of time; the thermal conductivity of rGO is normal, and most of the oxygen-containing groups on the rGO surface have been reduced, the PBX thermal stability is not affected adding rGO powder.

The activation energy in the HMX/GO composites is significantly increased when the GO add to HMX crystal, and the thermal stability of HMX explosive is increased ${ }^{[8]}$ because of the flame retardant effect, which is due to use many metal salts in the GO preparation process ${ }^{[9]}$. The desensitizing effect of GO sheets are better than fullerene and Carbon nanotubes (CNTs). Niu et al. ${ }^{[10]}$ have been prepared the HMX/rGO/graphite via an in situ chemical reduction coating method. These results suggest that GO sheet and graphite can be used as co-desensitizer in HMX explosive. In a word, thermal reactions at high temperature and pressure depend heavily on preparation method under different conditions. In fact, the results of thermal stability of HMX and CL-20 are opposite when the GO adds to the HMX and CL-20. On the other hand, the detail information of thermal decomposition mechanisms of Gr and GO in EMs/GBMs are still elusive under extreme conditions because of lacking experiment data.

Theoretical methods, such as quantum mechanics and molecular dynamic simulation, were reported to investigate the mechanisms of EMs/GBMs and clarify the effects on the sensitivity of GBMs adding to the EMs. For researching the mechanisms of functionalized graphene sheets (FGSs) adding and dispersing into the liquid nitromethane (NM), ab initio molecular dynamics simulations were calculated by Liu et al ${ }^{[11]}$. The results have been shown that the NM molecules and thermal decomposition products are greatly accelerating with the FGSs, forming water, nitrogen, and carbon dioxide. The reactions pathways, such as exchange of protons or oxygens, have been happened in the system and the FGSs play a catalyst role in the thermal decomposition process. Zhang el al. ${ }^{[12]}$ have been determined thermal stability of GO, ATRZ and GO-ATRZ, by using the ReaxFF-lg force field molecular dynamics simulations. because of the GO strong space effect, the activation energy of GO-ATRZ can increase $16.1 \mathrm{~kJ} / \mathrm{mol}$ comparison than the pure substance of ATRZ, indicating that the GO improve the thermal decomposition property of ATRZ. GO can be combined with ATRZ as a desensitizer candidate. The interaction interface of FOX-7-GO mixture composites ${ }^{[13]}$, which is an ideal prototype system, were studied by dispersion-corrected density functional approach. The results revealed that the interfacial charge transfer from FOX-7 to GO and hydrogen bonds are two important issues, leading to relatively strong interaction between FOX-7 and GO.

The thermal process of EMs/GBMs at high temperature and pressure, which are more complex than pure EMs, are accompanied by a large amount of energy release process. Furthermore, verifying the intermediates and initial reaction pathways of mixture systems at extreme conditions through the experiments, have been challenging. Molecules of explosives and $\mathrm{Gr}$ in EMs/GBMs involve unimolecular and bimolecular reactions through complex condensed decomposition process. Gr is the original type of GMBs. Understanding the role of $\mathrm{Gr}$ in mixture explosive is the based approach for reveal the decreasing sensitivity and complex detonation reactions. ReaxFF-lg molecular dynamics simulations (RMDS) ${ }^{[14]}$, which has been proposed by Liu et al, has been studied the reactions of $\mathrm{HMX}{ }^{[15]}$, ICM-102 ${ }^{[16]}$, TATB ${ }^{[17]}, \mathrm{CL}-20^{[18]}$, and CL-20/TNT. The fine results are compared with quantum mechanics calculations and experiments. 
In the present work, molecular configurations of single HMX molecule absorption on the Gr surface and HMX/Gr solid systems thermal decomposition at high temperature were studied using RMDS. This work focused on the thermal behaviors of perfect HMX crystal, HMX crystals with different crystal planes and HMX-Gr mixture systems. A deeply understanding of Gr effect in complex explosive chemical mechanisms and estimation of the different factors influence on the degradation pathways are essential for the applications of preparation, storage, transportation and use of mixed explosives utilization.

\section{Model Building And Computational Approach}

The perfect HMX crystal structure was obtained from experimental X-ray data ${ }^{[20]}$. Experiments showed that the shock sensitivity of HMX is different along different directions ${ }^{[21]}$. The compression results of $\beta$-HMX obtained from the diamond anvil cell have been shown that the lattice parameters of signal crystal are anisotropy ${ }^{[22]}$. In addition, the results of MD based on the COMPASS showed that the interactions between different HMX crystallographic plane and same binder are different ${ }^{[23]}$. The ReaxFF module of AMS software package with the 2019.304 version was carried in this work.

To research the crystal plane and Gr effect on the thermal decomposition of $\mathrm{HMX} / \mathrm{Gr}$, we built systemic models. Along $\mathrm{x}, \mathrm{y}$ and $\mathrm{z}$ directions, $4 \times 2 \times 3$ perfect HMX supercells and $8 \times 8 \times 1$ graphite supercells were employed with expanding with unit cell of HMX and graphite. Then (001), (010) and (100) structures were obtained, by cleaving perfect HMX supercell along (001), (010) and (100) crystal planes, respectively. So, the total HMX molecules of different crystal planes were 48 (1344 atoms). The initial lattice parameters of perfect HMX, (001), (010), and (100) crystal planes with HMX and HMX/Gr, which can be replaced as PHMX, P-001, P-010, P-100, M-001, M-010 and M-100 abbreviated forms, list in Table 1.

Table 1

Initial supercells of calculation systems

\begin{tabular}{|lllllllll|}
\hline Models & $\mathbf{a}(\AA)$ & $\mathbf{b}(\AA)$ & $\mathbf{c}(\AA)$ & $\mathbf{a}(\mathbf{d e g})$ & $\boldsymbol{\beta}(\mathrm{deg})$ & $\mathrm{Y}(\mathrm{deg})$ & $\boldsymbol{\rho}\left(\mathrm{g} / \mathrm{cm}^{3}\right)$ & atoms \\
\hline P-HMX & 26.16 & 22.10 & 26.10 & 90 & 124.3 & 90 & 1.894 & 1344 \\
\hline P-001 & 26.16 & 22.10 & 57.04 & 90 & 90 & 90 & 1.43 & 2688 \\
G-001 & 26.16 & 22.10 & 57.04 & 90 & 90 & 90 & 1.51 & 2816 \\
\hline P-010 & 26.10 & 24.41 & 53.10 & 90 & 90 & 62.27 & 1.58 & 2688 \\
\hline G-010 & 26.10 & 24.41 & 53.10 & 90 & 90 & 62.27 & 1.66 & 2816 \\
P-100 & 22.10 & 26.10 & 56.60 & 90 & 90 & 90 & 1.45 & 2688 \\
\hline G-100 & 22.10 & 26.10 & 56.60 & 90 & 90 & 90 & 1.52 & 2816 \\
\hline
\end{tabular}

Figure 1 and Fig. 2 display establishing processes of P-001 and M-001 models. For example, the model of P-001, which contains 96 HMX molecules, was built by making two (001) plane structures together. P-010 and P-100 models were established with the same methods. HMX/Gr model was built of $96 \mathrm{HMX}$ molecules with crystal planes and one graphene molecule. The graphene molecule, which was obtained from the graphite supercell of $8 \times 8 \times 1$, put in the middle of different crystal plane supercell. Finally, in the HMX/Gr model, graphene molecule mass fraction and HMX molecules mass fraction were $5.1 \%$ and $94.9 \%$, respectively.

Energy minimization without the optimization lattices was applied to release the internal structures stress of seven supercells. Subsequently, the two step RMDS, which was 25 ps isothermal-isobaric (NPT) MD (0.25 fs timestep) and 25 ps isothermal-isochoric (NVT) MD ( 0.25 fs timestep), were calculated to relax the seven structures at room temperature and pressure range from $1 \mathrm{~atm}$ to $31 \mathrm{GPa}$ with the Nose-Hoover chains (50 fs damping constant) and NPT NHCP anisotropic barostat (500 fs damping constant). Finally, based on the NVT ensemble, the total 100 ps RMDS ( $0.1 \mathrm{fs}$ timestep) were calculated to research the thermal decomposition at $3000 \mathrm{~K}$ with timestep of $0.1 \mathrm{fs}$. By analyzing the evolution of RMDS, behaviors of HMX molecules and Gr molecule were studied to reveal the Gr effect on the mixture explosive.

\section{Results And Discussion}

\subsection{Validation of ReaxFF-lg force field}

Confirming the applicability of the force field to the calculation system, is the basic work of molecular dynamics simulations. Many works were studied the applicability of the ReaxFF force field to the HMX and other EMs, reporting that the force field can well describe the equation of state of $\mathrm{HMX}{ }^{[14]}$ and the reaction process under different loading conditions ${ }^{[15-19]}$, but the applicability of the ReaxFF force field to the mixed system composed of HMX and graphene has never been studied.

To verify the ReaxFF-Ig force field fitting to HMX and graphene, the seven HMX systems of 25 ps NPT-MD and 25 ps NVT-MD at $300 \mathrm{~K}$ and normal pressure were performed. Our results of the lattice parameters and densities of P-HMX unit cell are summarized in Table 2 and compared to the experiment and other theory methods. The density result is $1.808 \mathrm{~g} / \mathrm{cm}^{3}$, which are agreed very well with earlier experiment ${ }^{[20-25]},{ }^{D F T}-D_{2}{ }^{[24]}$. 
Table 2

Lattice parameters of HMX unit cell compared with experiment and theory calculation

\begin{tabular}{|llllllll|}
\hline Models & $\mathbf{a}(\AA)$ & $\mathbf{b}(\AA)$ & $\mathbf{c}(\AA)$ & $\mathbf{a}(\mathbf{d e g})$ & $\boldsymbol{\beta}(\mathbf{d e g})$ & $\mathbf{Y}(\mathbf{d e g})$ & $\boldsymbol{\rho}\left(\mathbf{g} / \mathbf{c m}^{3}\right)$ \\
\hline Expt. [20] & 6.54 & 11.05 & 8.7 & 90 & 124.3 & 90 & 1.894 \\
\hline Expt. [21] & 6.537 & 11.054 & 8.702 & 90 & 124.44 & 90 & 1.897 \\
\hline DFT-D $_{2}{ }^{[24]}$ & 6.542 & 10.842 & 8.745 & 90 & 124.41 & 90 & 1.923 \\
\hline This work & 6.6 & 11.085 & 9.003 & 90 & 123.9 & 90 & 1.808 \\
\hline
\end{tabular}

The lattice parameters of different HMX crystal planes and HMX/Gr mixture systems are summarized in Table 3, which were predicted by ReaxFF-lg MD simulations. The densities, which are the mainly factor effect on the thermal decomposition process, have been the same values scales about $1.8 \mathrm{~g} / \mathrm{cm}^{3}$. As shown in Table 3, the values of a axis, b axis, $a, \beta$ and $y$ become little changes, while the value of $c$ axis change abruptly, indicating that the $c$ axis is easily compression.

Table 3

Lattice parameters of different crystal planes and $\mathrm{HMX} / \mathrm{Gr}$

\begin{tabular}{|llllllll|}
\hline Models & $\mathbf{a}(\AA)$ & $\mathbf{b}(\AA)$ & $\mathbf{c}(\AA)$ & $\mathbf{a}(\mathbf{d e g})$ & $\boldsymbol{\beta}(\mathbf{d e g})$ & $\mathbf{Y}(\mathrm{deg})$ & $\boldsymbol{\rho}\left(\mathbf{g} / \mathrm{cm}^{3}\right)$ \\
\hline P-001 & 26.67 & 20.63 & 46.99 & 90 & 90 & 90 & 1.816 \\
\hline G-001 & 25.41 & 20.25 & 45.69 & 90 & 90 & 90 & 1.827 \\
\hline P-010 & 28.05 & 25.89 & 40.12 & 90 & 90 & 61.5 & 1.821 \\
G-010 & 27.41 & 25.22 & 44.24 & 90 & 90 & 61.4 & 1.824 \\
\hline P-100 & 19.44 & 28.42 & 46.69 & 90 & 90 & 90 & 1.822 \\
\hline G-100 & 19.47 & 28.33 & 49.35 & 90 & 90 & 90 & 1.826 \\
\hline
\end{tabular}

Noteworthy, the interaction between $\mathrm{HMX} / \mathrm{Gr}$ mixture system can be expressed by binding energy, which has a positive correlation with the compatibility and stability. That is to say, the binding energy is bigger with the greater compatibility and stability of the mixture explosives. The binding energy can be calculated as:

$\mathrm{E}_{\text {bind }}=-\mathrm{E}_{\text {interaction }}=-\left(\mathrm{E}_{\mathrm{total}}-\mathrm{E}_{\mathrm{HMX}}-\mathrm{E}_{\mathrm{Gr}}\right)(1)$

Where $\mathrm{E}_{\mathrm{bind}}$ is the binding value in the $\mathrm{HMX} / \mathrm{Gr}$ system between $\mathrm{HMX}$ and graphene, and $\mathrm{E}_{\text {interaction }}$ is the interaction energy between the $\mathrm{HMX}$ and graphene in $\mathrm{HMX} / \mathrm{Gr}$ system. $\mathrm{E}_{\mathrm{total}}$ is the potential energy of $\mathrm{HMX} / \mathrm{Gr}$ system, $\mathrm{E}_{\mathrm{HMX}}$ and $\mathrm{E}_{\mathrm{Gr}}$ are the potential energy of $\mathrm{HMX}$ and graphene in the $\mathrm{HMX} / \mathrm{Gr}$ system with different crystal plane, which can be obtained by removing graphene and HMX. The largest and smallest binding energy systems prediction from RMDS studies are M-100 and M-010. He and coworkers ${ }^{[25]}$, investigated the interaction between different directions of HMX and Hydroxyl-terminated poly-butadiene (HTPB), which is a typical binder in plastic bonded explosives. They proposed that formation energy sequence between the HMX crystal and HTPB with different directions is the $(010) \otimes(001) \otimes(100)$. The interaction sequences of binding energy between the HMX directions with graphene and HTPB mean that the strong interaction intensity, like hydrogen bonds, is forming between different crystal surfaces and graphene, especially (010).

Table 4

The normalized binding energy of $\mathrm{HMX} / \mathrm{Gr}\left(\mathrm{kJ} \cdot \mathrm{mol}^{-1}\right)$
\begin{tabular}{|llllll|}
\hline Models & $\mathrm{E}_{\text {total }}$ & $\mathrm{E}_{\mathrm{HMX}}$ & $\mathrm{E}_{\text {graphene }}$ & $\mathrm{E}_{\text {bind }}$ \\
\hline M-001 & -5989.01 & -5485.16 & -488.16 & 15.69 \\
M-010 & -5991.61 & -5482.03 & -487.89 & 21.69 \\
M-100 & -5980.88 & -5484.23 & -488.28 & 8.37 \\
\hline
\end{tabular}

\subsection{Evolution of HMX molecules}

Decomposition reactions of solid HMX crystal at high temperature produced many small fragments and products by using RMDS ${ }^{[14]}$ and experiments ${ }^{[10]}$. Fig. 3 compares the decay number of HMX molecules in the thermal decomposition reactions of HMX and graphene mixture systems at $3000 \mathrm{~K}$. HMX molecules have the same trends in the initial stage during the $0-0.3 p s$, then with the different rate constants, HMX molecules are gradually disappeared with several initial reactions pathways during 0.31 ps -1.8 ps.

By approaching the first order phase transition nucleation theory and interatomic interaction model Monte Carlo simulation [26], the result of graphene melting temperature is $4510 \mathrm{~K}$, which is higher than the results of graphite. Especially, it is reported that the chemical bonds broken, and formation have been observed by using ab initio molecular dynamics calculations (AIMD), suggested that the graphene cannot melt when the system be heated up to $4500 \mathrm{~K}$, leading a quasi-2D liquid state ${ }^{[27]}$. It means that in this work, the graphene is still no reactive during the thermal decomposition of $\mathrm{HMX} / \mathrm{Gr}$ systems at $3000 \mathrm{~K}$. It can be confirmed that graphene and crystal face affect the decomposition process of HMX molecules in different calculation systems. 
The first stage of rate constant, which has been proposed to be critical component in the thermal decomposition, can be calculated by the number evolution of HMX molecule using the fist order reaction rate equation ${ }^{[18]}$ as

$$
N(t)=N_{0} \cdot \exp \left[-k_{1}\left(t-t_{0}\right)\right]
$$

2

where $N(t)$ and $N_{0}$ are the number of HMX molecules at time $t$ and $\mathrm{t}_{0}, t$ and $\mathrm{t}_{0}$ are the molecular dynamic simulations time. According to the equation, Fig. 4 shows the rate constant $\mathrm{k}_{1}$ of $\mathrm{HMX}$ molecules, it can be suggested that the crystal plane and graphene have both been changed the rate constant compared with pure HMX. Parameters of HMX molecules reactions in P-001, P-100, M-001, M-010, M-100 are both smaller than in P-HMX.

The rate constants of $\mathrm{HMX}$ molecules in $\mathrm{HMX} / \mathrm{Gr}$ is lower than with the same crystal plane of $\mathrm{HMX}$. The crystal plane of (010) can accelerate the thermal decomposition reactions of $\mathrm{HMX}$ molecules in P-010, whereas the rate constant of $\mathrm{k}_{1}$ is abruptly decreased when the graphene adds to the same crystal plane of HMX. The difference values between crystal plane and HMX/Gr of (001), (010) and (100) are $0.68 \mathrm{ps}^{-1}, 5.17 \mathrm{ps}^{-1}$ and $0.69 \mathrm{ps}^{-1}$, respectively. Thus, the graphene molecules have been shown great desensitized agent role in the HMX/Gr mixture systems, especially in the (010) crystal plane.

HMX have been exhibited the anisotropic responses under shock loadings by experiments and theory. Menikoff et al. ${ }^{[28]}$ measured the wave profiles of HMX, which is an elastic-plastic material, and calculated nonlinear and transient wave behavior using a rate-dependent elastic-plastic model. It is reported that the effective yield strength values of (011) and (010) are $0.18 \mathrm{GPa}$ and $0.31 \mathrm{GPa}$. Ge et al. ${ }^{[29]}$ performed AIMD conjunction with multiscale shock technique of HMX under different lattice vectors. Compared with shock wave propagation along the lattice vectors of $a, b$ and $c$, sliding rate of lattice vector $b$ is the smallest, suggesting the lattice vectors $b$ is main reason leading to anisotropic of HMX under shock loading. Interestingly, the results in our work suggest that graphene also has anisotropic reaction responses with the oriented of HMX crystal under thermal loading with different planes.

\subsection{Important intermediates fragments}

Decomposition pathways, intermediates and products of signal molecule and crystal structure under different loading have been reported by using DFT [30-35], AIMD ${ }^{[29,36,37]}$ and RMDS ${ }^{[38]}$. Initial pathways of $\mathrm{HMX}$ molecule are homolytic cleavage of $\mathrm{N}^{-\mathrm{NO}_{2}}$ bonds producing the $\mathrm{NO}_{2}$ radical, migration of $\mathrm{H}$ atom from the methylene forming $\mathrm{HONO}$, breaking four $\mathrm{C}-\mathrm{N}$ bonds in $\mathrm{HMX}$ molecule to form $\mathrm{CH}_{2} \mathrm{~N}_{2} \mathrm{O}_{2}$, isomerization of $\mathrm{NO}_{2}$ and then $\mathrm{C}-\mathrm{N}$ bond fracture occurs to release $\mathrm{N}_{2} \mathrm{O}_{2}$ fragments, $\mathrm{C}-\mathrm{H}$ bond dissociation. The simulation of theory results ${ }^{[26-27]}$ have also been suggested that the graphene molecule is not reactive lower than $4510 \mathrm{~K}$. Thus, in this work of HMX-Gr systems, the origin fragments of intermediates are from HMX molecules.

The evolution of fragment number with simulation time is a commonly used method for studying the mechanisms of EMs under different conditions. We calculated the fragments in seven models, using the bond order with 0.3 at $3000 \mathrm{~K}$. The results mean that $\mathrm{NO}_{2}, \mathrm{HONO}_{2} \mathrm{~N}_{2} \mathrm{O}_{2}, \mathrm{HNO}_{3}$ and $\mathrm{NO}_{\text {are }}$ the main intermediates in the thermal decomposition of pure $\mathrm{HMX}$ and $\mathrm{HMX}-\mathrm{Gr}$ systems, which are completely consistent with other calculations ${ }^{[36-38]}$ and experiments results ${ }^{[39-40]}$. The time evolution of $\mathrm{NO}_{2}$ radical fragments is presented in Fig. 5 at $3000 \mathrm{~K}$. Each plot shows results for the different $\mathrm{HMX}$ crystal plane and $\mathrm{HMX} / \mathrm{Gr}$ system. Maximum values of $\mathrm{NO}_{2}$ fragment per average mole of HMX molecules in P-HMX and P-001, P-010, P-100, G-001, G-010 and G100 supercell are $1.67 \mathrm{~mol}, 1.48 \mathrm{~mol}, 1.59 \mathrm{~mol}, 1.54 \mathrm{~mol}, 1.25 \mathrm{~mol}, 0.93 \mathrm{~mol}$ and $1.12 \mathrm{~mol}$, respectively.

Taking the perfect crystal $\mathrm{NO}_{2}$ fragments as a benchmark, the results show that the maximum values of $\mathrm{NO}_{2}$ fragments in other six calculation systems are lower than the benchmark value. Difference values between standard and P-001, P-010, P-100, M-001, M-010, M-100 and M-010 are 0.19 mol, 0.06 mol, 0.13 $\mathrm{mol}, 0.42 \mathrm{~mol}, 0.74 \mathrm{~mol}$, and $0.55 \mathrm{~mol}$, respectively. With the addition of graphene, the curves of nitro radical change with time are obviously different. The models of G-001, G-010 and G-100 are shown in Fig. 6, which the view is XZ plane, meaning that along the (010) direction, the biggest steric hindrance in $\mathrm{HMX} / \mathrm{Gr}$ is $\mathrm{G}-010$ because of the $\mathrm{NO}_{2}$ functional groups. Steric hindrance effect of $\mathrm{NO}_{2}$ functional groups and the interaction between graphene and $\mathrm{HMX}$ explosive molecules, lead to the inhibition of graphene on the initial decomposition reaction pathway of HMX explosive molecules, which is directional and selective on the 010-crystal plane.

To evaluation the effect of crystal plane and graphene in the $\mathrm{HMX} / \mathrm{Gr}$ thermal decomposition simulations, the relationships of $\mathrm{HONO}, \mathrm{N}_{2} \mathrm{O}_{2}$, $\mathrm{HNO}_{3}$ and $\mathrm{NO}$ values between time are shown in Fig. 7. $\mathrm{HNO}_{3}, \mathrm{NO}$ and $\mathrm{N}_{2} \mathrm{O}_{2}$ values of fragments are changed more gradually than the same plots values of $\mathrm{HONO}$ in $\mathrm{P}$ - $\mathrm{HMX}$ and other simulations systems.

The rate constants of intermediates were obtained using equation 2 in the simulation time range from maximum formation populations to zero at $3000 \mathrm{~K}$, list in Tab. 5. As can been seen, the rate constants of $\mathrm{HONO}$ and $\mathrm{N}_{2} \mathrm{O}_{2}$ are both increased in the HMX/Gr compared with P-HMX. While the NO rate constants are not changed in the thermal decomposition process in the seven system. Whereas $\mathrm{NO}_{2}$ rate constants show complex behaviors in the different system.

Moreover, the rate constants of $\mathrm{NO}_{2}$ in $\mathrm{P}-010$ and $\mathrm{P}-100$ changed abruptly compared with $\mathrm{P}-\mathrm{HMX}$. This trend has been changed when the graphene mixtures with HMX in the M-001 and M-010. 
Table 5

Rate constants of intermediates at $3000 \mathrm{~K}$

$\left(\mathrm{ps}^{-1}\right)$

\begin{tabular}{|lllll|}
\hline Models & $\mathrm{NO}_{2}$ & HONO & $\mathrm{NO}$ & $\mathrm{N}_{2} \mathrm{O}_{2}$ \\
\hline P-HMX & 0.32 & 0.14 & 0.12 & 0.16 \\
\hline P-001 & 0.30 & 0.18 & 0.12 & 0.24 \\
\hline P-010 & 0.49 & 0.19 & 0.13 & 0.23 \\
\hline P-100 & 0.46 & 0.17 & 0.11 & 0.18 \\
\hline M-001 & 0.38 & 0.19 & 0.10 & 0.18 \\
\hline M-010 & 0.3 & 0.23 & 0.10 & 0.29 \\
\hline M-100 & 0.4 & 0.17 & 0.11 & 0.22 \\
\hline
\end{tabular}

Crystal planes and graphene molecules do not affect the initial decomposition pathways of HMX molecules in P-HMX and other systems, while the total amount populations of intermediates and the rate constants in $\mathrm{HMX} / \mathrm{Gr}$ mixture systems are abruptly changed compared with the perfect $\mathrm{HMX}$ and different crystal planes supercells.

\subsection{Fragments formation on graphene surface}

The absorption properties of HMX molecules on $\mathrm{Gr}$ in HMX/Gr system at room temperature and pressure range from $1 \mathrm{~atm}$ to $31 \mathrm{GPa}$ were obtained. We found that there are 3, 5 and 3 different $\mathrm{HMX}$ signal molecule configurations bonding on the Gr. At normal temperature and 1 atm, the $\mathrm{HMX}$ molecules bonding on the graphene can be described as two types as shown in Fig. 8. One is three $\mathrm{C}_{4} \mathrm{H}_{8} \mathrm{O}_{6} \mathrm{~N}_{8} \mathrm{O}(\text { ads) })_{2}$ in $\mathrm{M}-001$ and $\mathrm{M}-100$, while the other is one $\mathrm{C}_{4} \mathrm{H}_{8} \mathrm{O}_{7} \mathrm{~N}_{8} \mathrm{O}($ ads) molecule in $\mathrm{M}-010$. The chemical structural formula of $\mathrm{C}_{4} \mathrm{H}_{8} \mathrm{O}_{7} \mathrm{~N}_{8} \mathrm{O}$ (ads) indicates that an oxygen atom is adsorbed on the surface of graphene. All $\mathrm{HMX}$ molecules absorption on Gr locate at the Gr edge. In the M-001 and M-100, two oxygen atoms in the nitro functional groups of three HMX molecules are adsorbed on the graphene surface as shown in the figure $8 \mathrm{a}$ and $8 \mathrm{c}$, while in the $\mathrm{M-010}$, one oxygen atom in the nitro functional group of one HMX molecule is adsorbed on the graphene surface as shown in the figure $8 \mathrm{~b}$. This change shows that the interaction between HMX and graphene on different crystal planes is different.

To further study the amount of HMX molecules adsorbed on the surface of graphene at different pressures, taking the supercell of HMX/Gr at normal pressure and room temperature as the starting point, the structure of supercell at $300 \mathrm{~K}$ and different pressures was calculated. The number distribution of $\mathrm{HMX}$ molecules adsorbed on the surface of graphene was analyzed. The results show that the nitro functional groups on the A-axis and E-axis of single molecule HMX can be adsorbed on the surface of graphene. At the pressure range between 1GPa to 31GPa, HMX molecules with two different configurations are adsorbed on the graphene surface along the (001) surface. In one configuration shown in figure $9 \mathrm{a}$, the one oxygen atom in nitro functional group is adsorbed on the graphene surface, which can be descripted as $\mathrm{C}_{4} \mathrm{H}_{8} \mathrm{O}_{7} \mathrm{~N}_{8} \mathrm{O}$ (ads), and in the other configuration shown in figure $9 \mathrm{~b}$, one $\mathrm{N}$ atom and two $\mathrm{O}$ atoms in the nitro functional group are adsorbed on the surface with the chemical structural formula of $\mathrm{C}_{4} \mathrm{H}_{8} \mathrm{O}_{6} \mathrm{~N}_{7} \mathrm{~N}$ (ads) $\mathrm{O}$ (ads) 2 . In the same pressure range, along the (100) plane shown in figure 9c, the first configuration of $\mathrm{HMX}$ molecule absorption on the Gr is that the $\mathrm{N}$ atom in the $\mathrm{CN}$ ring constituting of $\mathrm{HMX}$ ring bonding on the graphene surface with the chemical formula $\mathrm{C}_{4} \mathrm{H}_{8} \mathrm{O}_{8} \mathrm{~N}_{7} \mathrm{~N}$ (ads), the second configuration is that the one of $\mathrm{O}$ atom in nitro functional group in the $\mathrm{HMX}$ molecule adsorbed on the graphene surface shown in figure $9 \mathrm{~d}$, and two molecules of this configuration with the chemical formula of $\mathrm{C}_{4} \mathrm{H}_{8} \mathrm{O}_{7} \mathrm{~N}_{8} \mathrm{O}$ (ads) are located above and below the graphene surface respectively.

In the same pressure range, there are four configurations of single molecule $\mathrm{HMX}$ adsorbed on graphene surface along (010) surface as shown in Fig. 10. In the first configuration, two $\mathrm{O}$ atoms in a nitro functional group of $\mathrm{HMX}$ molecule are adsorbed on the surface of graphene with the $\mathrm{C}_{4} \mathrm{H}_{8} \mathrm{O}_{6} \mathrm{~N}_{8} \mathrm{O}(\mathrm{ads}){ }_{2}$, in the second configuration, the $\mathrm{N}$ atom of $\mathrm{CN}$ ring in $\mathrm{HMX}$ molecule is adsorbed on the surface of graphene with the $\mathrm{C}_{4} \mathrm{H}_{8} \mathrm{O}_{8} \mathrm{~N}_{7} \mathrm{~N}($ ads), and in the third configuration, the $\mathrm{O}$ atom in a nitro functional group of $\mathrm{HMX}$ molecule and the $\mathrm{N}$ atom in $\mathrm{CN}$ ring are adsorbed on the surface of graphene with the $\mathrm{C}_{4} \mathrm{H}_{8} \mathrm{O}_{7} \mathrm{~N}_{7} \mathrm{O}($ ads) $\mathrm{N}($ ads), the fourth $\mathrm{HMX}$ molecular configuration with the chemical formula $\mathrm{C}_{4} \mathrm{H}_{8} \mathrm{O}_{4} \mathrm{~N}_{8} \mathrm{O}$ (ads) ${ }_{4}$ is two nitro functional groups, in which four $\mathrm{O}$ atoms are adsorbed on the surface of graphene. Compared with the M-001 and M-100 systems, the HMX molecules absorption on M-010 systems at high pressure are more complex, two nitro functional of HMX molecule can be bonding on the $\mathrm{Gr}$, which is the important factor effect on the stable of HMX at extremely conditions.

Figure 11 shows the number of HMX molecules adsorbed on the graphene surface in the HMX/Gr mixed system along different crystal planes at atmospheric pressure to $31 \mathrm{GPa}$. It can be seen that, except for $19 \mathrm{GPa}, 21 \mathrm{GPa}$ and $23 \mathrm{GPa}$, in the remaining pressure range, the number of molecules adsorbed on the graphene surface by HMX molecules along (010) plane is less than that adsorbed on the graphene surface along (001) plane and (100) plane.

The chemical process in $\mathrm{HMX} / \mathrm{Gr}$ in condensed phase at $3000 \mathrm{~K}$ is more complex than in pure HMX supercell, the initial reaction pathways of HMX molecules experienced difference. Moreover, the fragments in $\mathrm{HMX} / \mathrm{Gr}$ are obvious changed with crystal plane. Table. 6 shows the main products and types on graphene surface at $3500 \mathrm{~K}$ and $100 \mathrm{ps}$. Take $\mathrm{A} \times \mathrm{B}(\mathrm{ads}) \mathrm{C}$ for example to describe the specific meaning of each item, where $A$ represents the number of fragments on graphene, $\mathrm{B}(\mathrm{ads})$ represents the types of atoms bonded to the surface of graphene, and $\mathrm{C}$ represents the number of bonding $\mathrm{B}$ atoms. The types of decomposition product fragments generated by M-001, M-010 and M-100 on the surface of graphene are 25, 34 and 31, respectively. M-010 mixed system produces the most kinds of decomposition product fragments.

The amount of $\mathrm{O}(\mathrm{ads})$ is the largest in $\mathrm{M}-001$, while $\mathrm{O}(\mathrm{ads}), \mathrm{OC}(\mathrm{ads})$ and $\mathrm{HO}$ (ads) values are the largest in $\mathrm{M}-010$ and $\mathrm{M}-100$. This change indicates that at the action of high temperature, the fragments generated by HMX explosive react with the $\mathrm{C}$ atoms on the surface of graphene to form different kinds of 
products, which further reduce the reaction rate constants of $\mathrm{HMX}$ molecules, prolong the decomposition time of HMX molecules, and improve the sensitivity of HMX explosive after adding graphene.

Table 6 The total types and amount of fragments formation on the graphene surface

\begin{tabular}{|c|c|}
\hline System & Fragments on the graphene surface \\
\hline M-001 & 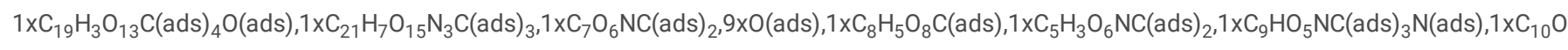 \\
\hline M-010 & $1 \times \mathrm{C}_{13} \mathrm{H}_{3} \mathrm{O}_{9} \mathrm{C}(\mathrm{ads}), 1 \times \mathrm{CC}_{26} \mathrm{H}_{3} \mathrm{O}_{20} \mathrm{~N}_{3} \mathrm{C}(\mathrm{ads})_{8} \mathrm{O}(\mathrm{ads})_{2,}, 12 \times \mathrm{HO}(\mathrm{ads}), 1 \mathrm{xC}_{16} \mathrm{H}_{2} \mathrm{O}_{8} \mathrm{~N}_{4} \mathrm{C}(\mathrm{ads})_{5}, 1 \mathrm{xC}_{10} \mathrm{H}_{4} \mathrm{O}_{6} \mathrm{NC}(\mathrm{ads})_{3}, 1 \times \mathrm{C}_{5} \mathrm{HO}{ }_{2} \mathrm{O}$ (ads) $\mathrm{N}(\mathrm{ads}), 10 \times \mathrm{OC}(\mathrm{ads}), 2 \times \mathrm{CHO}$ \\
\hline 100 & $1 \times \mathrm{C}_{10} \mathrm{H}_{3} \mathrm{O}_{10} \mathrm{C}(\mathrm{ads}), 1 \mathrm{xC}_{10} \mathrm{HO}_{8} \mathrm{~N}_{2} \mathrm{C}(\mathrm{ads}), 1 \mathrm{xC}_{2} \mathrm{H}_{3} \mathrm{O}_{3} \mathrm{C}(\mathrm{ads})_{3}, 1 \mathrm{xCH}_{2} \mathrm{O}_{3} \mathrm{O}$ (ads), $1 \mathrm{xC}_{3} \mathrm{O}_{3} \mathrm{C}\left(\right.$ ads) ${ }_{2} \mathrm{O}(\mathrm{ads}), 18 \times \mathrm{O}$ (ads), $1 \times \mathrm{COC}(\mathrm{ads})_{2}, 1 \times \mathrm{C}_{10} \mathrm{H}_{2} \mathrm{O}_{8} \mathrm{C}(\mathrm{ads}), 1 \times \mathrm{C}_{13} \mathrm{H}_{3}$ \\
\hline
\end{tabular}

Figure 12 shows the value changes of $\mathrm{O}$ (ads) in $\mathrm{HMX} / \mathrm{Gr}$ with simulation time. As can been seen, three system of $\mathrm{O}$ (ads) fragments have the same trends. The number of $\mathrm{O}$ (ads) increases quickly during the time range from 0 ps to $10.2 \mathrm{ps}$, decreases slowly between $10.3 \mathrm{ps}$ to $71.5 \mathrm{ps}$, then keeps at the the equilibrium position at 71.6ps-100ps. The maximum values sequence of $\mathrm{O}$ (ads) is $\mathrm{M}-010>\mathrm{M}-100>\mathrm{M}-001$.

The time evolutions of the population of $\mathrm{HO}$ (ads) and OC (ads) are displayed in Fig. 13a and Fig. 13b. In M-001, M-010 and M-100 systems at 3000K, fragments of $\mathrm{HO}$ (ads) fluctuate at 4, 8 and 6, respectively. While fragments of OC (ads) fluctuate at 3.5, 8.3 and 7.0. The evolution populations of HO (ads) and $\mathrm{OC}$ (ads) indicate that $\mathrm{HO}$ (ads) and OC (ads) reached equilibrium in the simulation time in the same order as $\mathrm{O}$ (ads), but $\mathrm{HO}$ (ads) and OC (ads) do not show obvious peak values.

The results of fragments evolution on the graphene surface in $\mathrm{HMX} / \mathrm{Gr}$ with different crystal plane, show that the initial decomposition pathways of HMX/Gr are the $\mathrm{C}$ atoms in graphene react with the intermediates, forming $\mathrm{C}=\mathrm{O}$ bonds, $\mathrm{C}-\mathrm{OH}$ bonds and $\mathrm{C}-\mathrm{CO}$ bonds between $\mathrm{C}$ atoms and nitro radicals, hydroxyl radical and $\mathrm{CO}$ at $3000 \mathrm{~K}$. Comparing the products distribution of three different crystal planes, it shows that the type and quantity of graphene products are the largest along the (010) crystal plane, and the decomposition reaction of $\mathrm{HMX} / \mathrm{Gr}$ at high temperature is directional and selective, which provides theoretical guidance for the formulation design and safety improvement of graphene based explosives.

\subsection{Final products of small fragments}

Final products, like $\mathrm{N}_{2}, \mathrm{H}_{2} \mathrm{O}, \mathrm{CO}_{2}$, and $\mathrm{CO}$, in the thermal decomposition process were analyzed using bond order cutoff of 0.3 . The products evolutions during the simulation time are presented in Fig. 14. It is suggested that small products are appeared quickly at the beginning of the simulation between 0 to 20 ps, then kept a plateau status between $20.1 \mathrm{ps}$ to 100 ps. This implies that graphene and crystal do not affect the kinetic parameters of the final products.

\section{Conclusions}

In this work, ReaxFF molecular dynamic simulations were performed to study the initial thermal decomposition reactions of HMX and graphene mixture systems with different crystal planes. By analyzing the lattice parameters, binding energy, rate constants, evolution of intermediates and products fragments, the thermal stability of $\mathrm{HMX}$ is strongly dependent on the crystal plane and graphene; sensitive for thermal stability of $\mathrm{HMX}$ and $\mathrm{HMX} / \mathrm{Gr}$ with the (010), but less sensitive for thermal stability of $\mathrm{HMX} / \mathrm{Gr}$ with the (001) and (100) which the HMX molecules of reaction rate constants in M-001 and M-010 were obviously changed lower.

The intermediates trends of $\mathrm{NO}_{2}$ radicals, $\mathrm{HONO}, \mathrm{NO}, \mathrm{N}_{2} \mathrm{O}_{2}$ and $\mathrm{HNO}_{3}$ versus temperature relationship at $3000 \mathrm{~K}$ were obtained. The graphene adding to the $\mathrm{HMX}$ crystal along (010) plane abruptly improves the maximum value of these intermediates. Our results also indicated that the homolytic cleavage of $\mathrm{N}^{-\mathrm{NO}_{2}}$ and HONO elimination are the mainly primary pathways for HMX molecules in $\mathrm{HMX} / \mathrm{Gr}$ in the early stages under high temperature. Moreover, the observation of crystal plane along (010), $\mathrm{NO}_{2}$ radical formation is suppressed with the adding graphene. At high pressure ranging from normal pressure to $31 \mathrm{GPa}$ and 300 $\mathrm{K}$, absorption properties of $\mathrm{HMX}$ molecules on Gr surface were studied. $\mathrm{O}$ atoms and $\mathrm{N}$ atoms in nitro functional group and $\mathrm{N}$ atoms of $\mathrm{HMX}$ ring are the main atoms absorption on the Gr surface. Along the (010) plane, the values of HMX molecules are lower than that the HMX molecules in M-100 and M-001 systems.

Basing on the intermediate population analysis on graphene molecules, the main reaction pathway of graphene in $\mathrm{HMX} / \mathrm{Gr}$ thermal decomposition was obtained. The graphene does not change the mechanisms of HMX molecule in the HMX/Gr systems and the different kind sequences of product fragments are $\mathrm{M}-010>\mathrm{M}-100>\mathrm{M}-001$. When adding the graphene to the HMX model with different crystal plane, the carbon atom in graphene can easily form carbonyl, hydroxyl and - $\mathrm{CO}$ bonds and produce $\mathrm{O}(\mathrm{ads}), \mathrm{OC}(\mathrm{ads})$ and $\mathrm{HO}$ (ads) fragments. These changed relationships of graphene in $\mathrm{M}-010$ are higher than those obtained in M-001 and M-100.

\section{Declarations}

Funding: The author thanks the Shanxi Province Teaching Reform Project of Colleges and Universities under Grant Nos.2020405.

Conflicts of interest/Competing interests: I declare that I do not have any commercial or associative interest that represents a conflict of interest in connection with the work submitted.

Availability of data and material: The data used to support the findings of this study are available from the corresponding author upon request.

Code availability: The ReaxFF module of AMS(Amsterdam Modeling Suite) software package with the 2019.304 version was carried in this work. 
Authors' contributions: Li Zhang performed the simulations and the data analyses, the author also wrote the manuscript.

\section{References}

1. Fried LE, Manaa MR, Pagoria PF et al (2001) Design and synthesis of energetic materials 1 [J]. Annu Rev Mater Sci 31(1):291-321

2. Singh H (2005) Current trend of R\&D in the field of high energy materials (HEMS) - an overview. Explosion 15:120-133

3. Allen MJ, Tung VC, Kaner RB (2009) Honeycomb carbon: a review of graphene[J]. Chem Rev 110(1):132-145

4. Chen LY, Zhao SX, Yang PJ et al (2006) The coating and desensitization of CL-20[J]. Chinese Journal of Energetic Materials 14(3):171-173

5. Lin C, He G, Liu J et al (2017) Enhanced non-linear viscoelastic properties of polymer bonded explosives based on graphene and a neutral polymeric bonding agent[J]. Cent Eur J Energ Mater 14(4):788-805

6. Yu L, Ren H, Guo X-Y et al (2014) A novel epsilon-HNIW-based insensitive high explosive incorporated with reduced graphene oxide [J]. J Therm Anal Calorim 117(3):1187-1199

7. Liu J, Ren H, Jiao QJ et al (2014) The influence of GO/RGO on the thermal decomposition of HNIW [J]. Integrated Ferroelectrics 152(1):127-136

8. Li R, Wang J, Shen JP et al (2013) Preparation and characterization of insensitive HMX / graphene oxide composites [J]. Propellants, Explosives, Pyrotechnics, 38(6): 798-804

9. Shi Y, Li LJ (2011) Chemically modified graphene: flame retardant or fuel for combustion? [J]. J Mater Chem 21(10):3277-3279

10. Niu C, Jin B, Peng R et al (2017) Preparation and characterization of insensitive HMX/rGO/G composites via in situ reduction of graphene oxide[J]. RSC Adv 7(51):32275-32281

11. Liu LM, Car R, Selloni A et al (2012) Enhanced thermal decomposition of nitromethane on functionalized graphene sheets: ab initio molecular dynamics simulations [J]. J Am Chem Soc 134(46):19011-19016

12. Zhang CM, Fu XL, Li JZ et al (2019) Desensitizing effect of graphene oxide on thermolysis mechanisms of 4,4'-azo-1,2,4-triazole studied by reactive molecular dynamics simulations [J]. The Journal of Physical Chemistry A 123:7, 1285-1294

13. Su Y, Sun YZ, Zhao JJ (2019) Interaction mechanisms of insensitive explosive FOX-7 and graphene oxides from ab initio calculations [J]. Nanomaterials 9(9):1290-1299

14. Liu LC, Liu Y, Zybin SV et al (2011) ReaxFF-Ig: correction of the ReaxFF reactive force field for London dispersion, with applications to the equations of state for energetic materials[J]. J Phys Chem A 115:11016-11022

15. Wu JY, Yang LJ, Li YJ et al (2020) Microscopic mechanisms of femtosecond laser ablation of HMX from Reactive molecular dynamics simulations[J]. J Phys Chem C 124(21):11681-11693

16. Yang K, Chen L, Liu DY et al (2020) Anisotropic initial reaction mechanism and sensitivity characterization of the layered crystal structure explosive ICM102 under shock loading[J]. J Phys Chem C 124(19):10367-10375

17. Hamilton BW, Kroonblawd MP, Islam Md M et al (2019) Sensitivity of the shock initiation threshold of 1,3,5-Triamino-2,4,6-trinitrobenzene (TATB) to nuclear quantum effects[J]. J Phys Chem C 123(36):21969-21981

18. Wang FP, Chen L, Geng DS et al (2019) Molecular dynamics simulations of an initial chemical reaction mechanism of shocked CL-20 crystals containing nanovoids[J]. J Phys Chem C 123(39):23845-23852

19. Ren CX, Li XX, Guo L (2019) Chemical insight on decreased sensitivity of CL-20/TNT cocrystal revealed by ReaxFF MD simulations[J]. J Chem Inf Model 59(5):2079-2092

20. Choi CS, Boutin HPA (1970) Study of the crystal structure of $\beta$-cyclotetra-methylene tetranitramine by neutron diffraction[J]. Acta Crystallogr Sect B $26: 1235-1240$

21. Hooks DE, Menikoff R, Dick JJ (2005) Analysis of wave profiles for single crystal cyclotetramethylene tetranitramine[J]. J Appl Phys 97(2):023529023535

22. Hooks DE, Hayes DB, Hare DE et a1. Isentropic compression of cyclotetramethylene tetranitramine (HMX) single crystals to $50 \mathrm{GPa}[\mathrm{J}]$. Journal of Applied Physics,2006, 99(12): 124901-124906

23. Xiao JJ, Fang GY, Ji GF et al (2005) Simulation investigations in the binding energy and mechanical properties of HMX-based polymer-bonded explosives[J].Science Bulletin, (1),21-26

24. Peng Q, Rahul, Wang GY et al (2014) Structures, mechanical properties, equations of state, and electronic properties of $\beta$-HMX under hydrostatic pressures: a DFT-D2 study [J]. Phys Chem Chem Phys 16:19972-19983

25. He ZH, Chen J, Ji GF et al (2015) Dynamic responses and initial decomposition under shock loading: a DFTB calculation combined with MSST method for $\beta$-HMX with molecular vacancy[J]. J Phys Chem B 119(33):10673-10681

26. Los JH, Zakharchenko KV, Katsnelson MI et al (2015) Melting temperature of graphene[J]. Phys Rev B: Condens Matter Mater Phys 91:045415-045420

27. Ganz E, Ganz AB, Yang LM et al (2017) The initial stages of melting of graphene between $4000 \mathrm{~K}$ and $6000 \mathrm{~K}[\mathrm{~J}]$. Physical Chemistry Chemical Physics 19(5):3756-3762

28. Menikoff R, Dick JJ, Hooks DE (2005) Analysis of wave profiles for single-crystal cyclotetramethylene tetranitramine[J]. J Appl Phys 97:023529

29. Ge NN, Wei YK, Song ZF et al (2014) Anisotropic responses and initial decomposition of condensed-phase $\beta$-HMX under shock loadings via molecular dynamics simulations in conjunction with multiscale shock technique[J]. Journal of Physical Chemistry B 118(29):8691-8699 
30. Lewis JP, Sewell TD, Evans RB et al (2000) Electronic structure calculation of the structures and energies of the three pure polymorphic forms of crystalline HMX[J]. Journal of Physical Chemistry B 104(5):1009-1013

31. Lewis JP, Glaesemann KR, Van Opdorp K et al (2000) Ab initio calculations of reactive pathways for a-octahydro- 1,3,5,7-tetranitro-1,3,5,7-tetrazocine (a-HMX)[J]. J Phys Chem A 104(48):11384-11389

32. Lyman JL, Liau YC, Brand HV (2002) Thermochemical functions for gas-phase, 1,3,5,7-tetranitro-1,3,5,7-tetraazacyclooctane (HMX), its condensed phases, and its larger reaction products[J], vol 130. Combustion \& Flame, pp 185-203. 3

33. Zhang SW, Nguyen HN, Truong TN (2003) Theoretical study of mechanisms, thermodynamics, and kinetics of the decomposition of gas-phase a-HMX (Octahydro-1,3,5,7-tetranitro-1,3,5,7-tetrazocine)[J]. Journal of Physical Chemistry B 107(16):2981-2989

34. Cobos CJ (2005) DFT study of the thermochemistry of gas-phase 1,3,5,7-tetranitro-1,3,5,7-tetraazacyclooctane ( $\beta$-HMX) [J]. J Mol Struct (Thoechem) 714(2-3):147-152

35. Sharia O, Kuklja MM (2010) Ab initio kinetics of gas phase decomposition reactions[J]. J Phys Chem A 114(48):12656-12661

36. Manaa MR, Fried LE, Melius CF et al Decomposition of HMX at extreme conditions: a molecular dynamics simulation[J].Journal of Physical Chemistry A,2002,106(39):9024-9029

37. Ge NN, Wei YK, Ji GF et al (2012) Initial decomposition of the condensed-phase $\beta-H M X$ under shock waves: molecular dynamics simulations[J]. Journal of Physical Chemistry B 116(46):13696-13704

38. Zhou TT, Huang FL (2011) Effects of defects on thermal decomposition of HMX via ReaxFF molecular dynamics simulations[J]. Journal of Physical Chemistry B 115(2):278-287

39. Jr RB, Bulusu S (1991) Thermal decomposition of energetic materials. 2. Deuterium isotope effects and isotopic scrambling in condensed-phase decomposition of octahydro - 1,3,5,7 - tetranitro - 1,3,5,7 - tetrazocine[J]. J Phys Chem 95(15):5838-5845

40. Shaw R, Walker FE (1977) Estimated kinetics and thermochemistry of some initial unimolecular reaction in the thermal decomposition of 1,3,5,7tetranitro-1,3,5,7-tetrazaacyclootane in the gas phase[J]. J Phys Chem 81(25):2572-2576

\section{Figures}

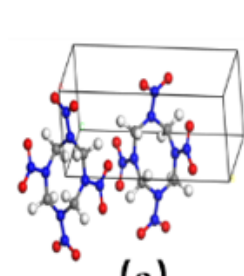

(a)

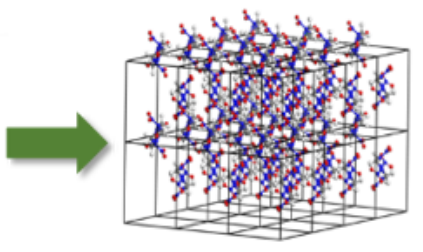

(b)

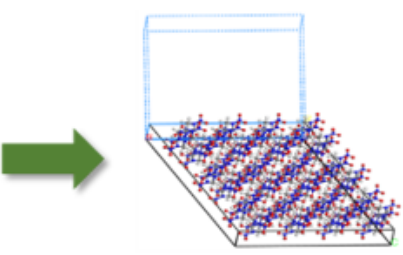

(c)

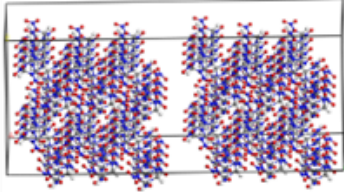

(e)

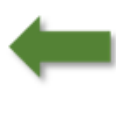

.

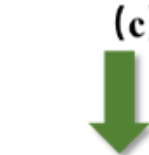

\section{Figure 1}

The process of establishing P-001 model. (a) the unit cell of $\beta$-HMX containing two HMX molecules with a ring-chain structure. (b) supercell of $\beta$-HMX crystal with $4 \times 2 \times 3$, containing $48 \mathrm{HMX}$ molecules. (c) cleaving perfect $\beta$-HMX crystal along (001) crystal plane. (d) the two structures of (001) crystal plane. (e) the final structure of P-001. 


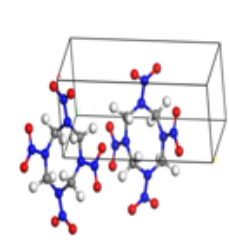

(a)

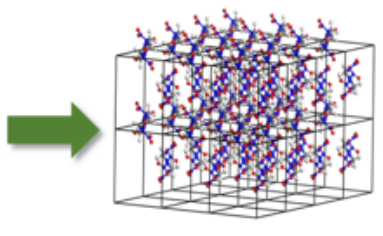

(b)

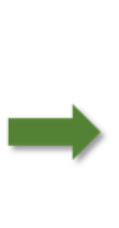

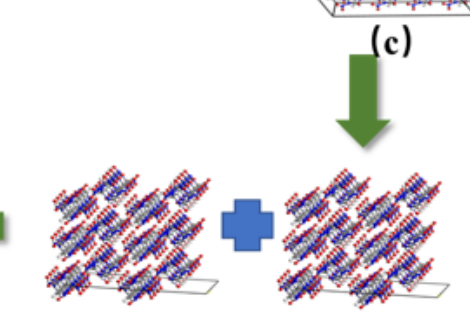

(f)

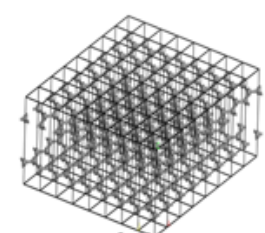

(e)

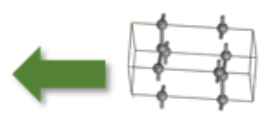

(d)

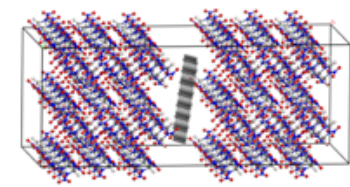

(h)
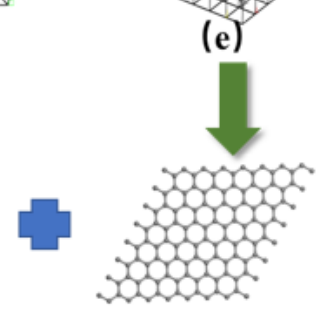

(g)

Figure 2

The process of establishing G-001 supercell. (a) and (d) the unit cells of $\beta$-HMX and graphite. (b) and (e) supercells of $\beta$-HMX with $4 \times 2 \times 3$ and graphite with $8 \times 8 \times 1$. (c) cleaving perfect $\beta$-HMX crystal along (001) crystal plane. (f) and (g) the structures of (001) crystal plane and graphene. (e) the final structure of G001.

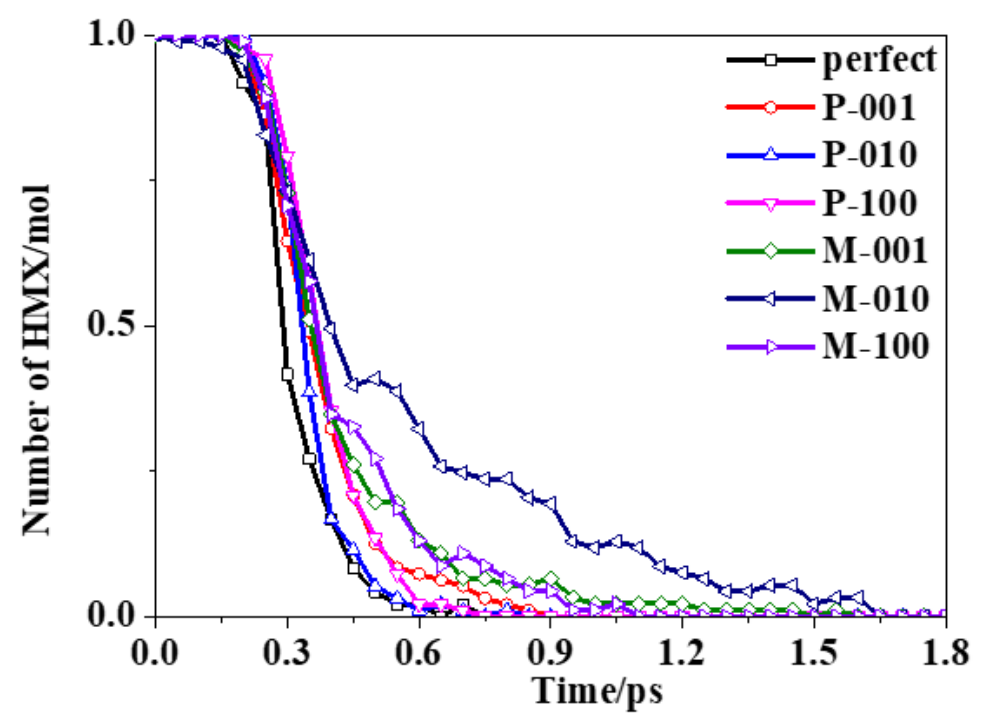

Figure 3

Decay of HMX molecules versus simulation time at $3000 \mathrm{~K}$ 


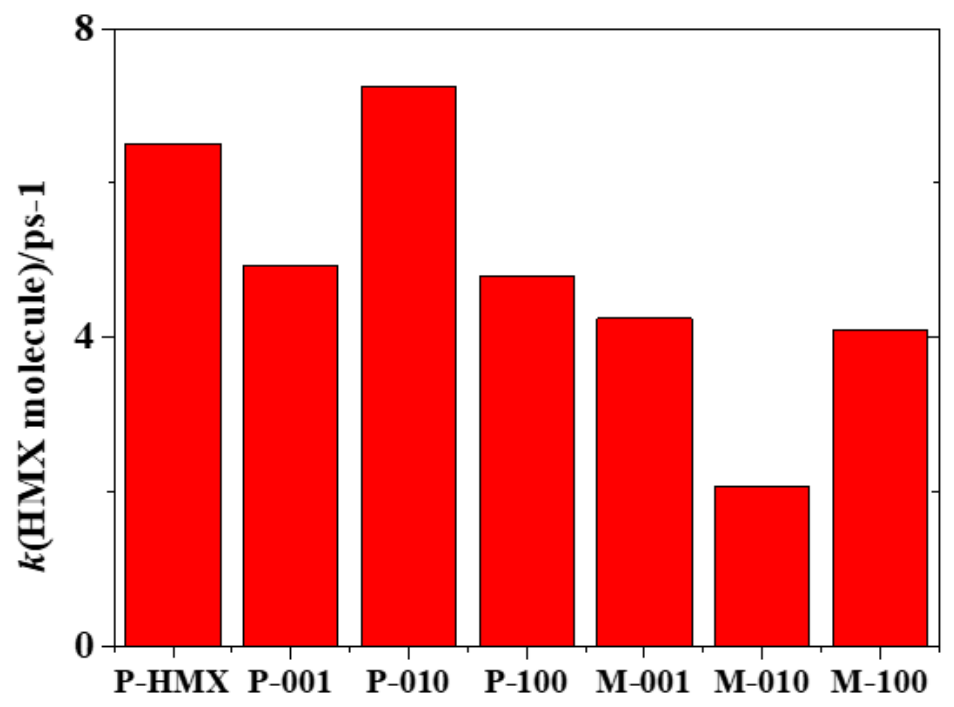

Figure 4

Reaction rate constants of $\mathrm{HMX}$ molecules at $3000 \mathrm{~K}$

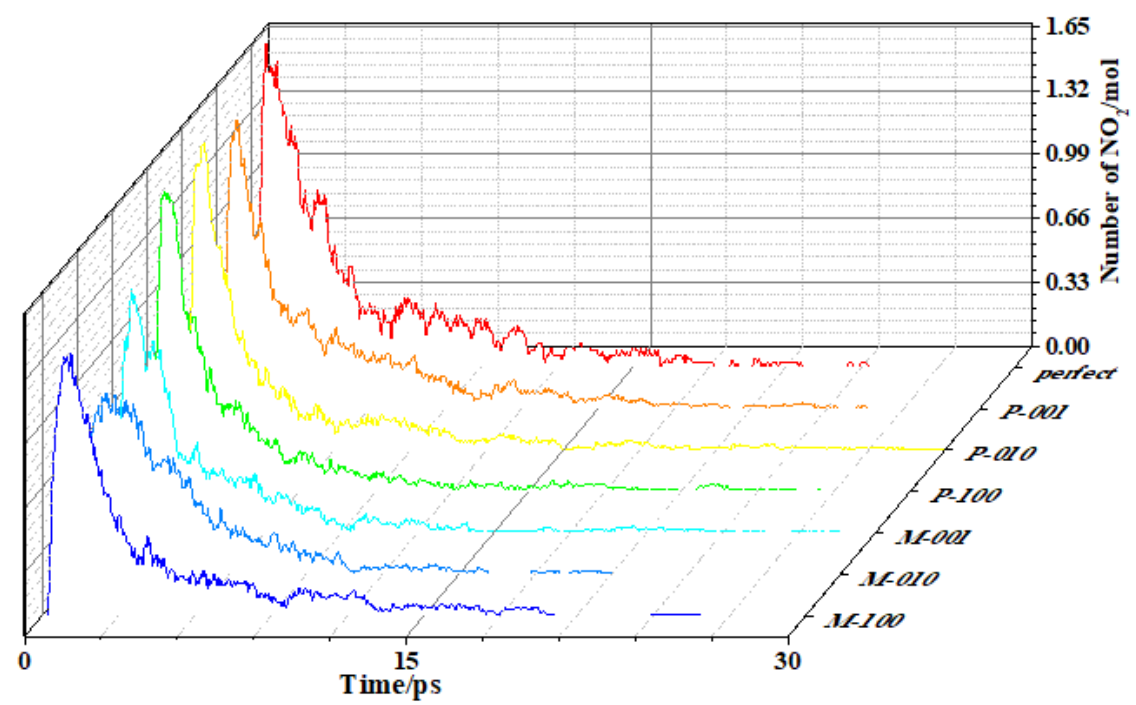

Figure 5

Evolutions of $\mathrm{NO}_{2}$ radical fragments at $3000 \mathrm{~K}$ 


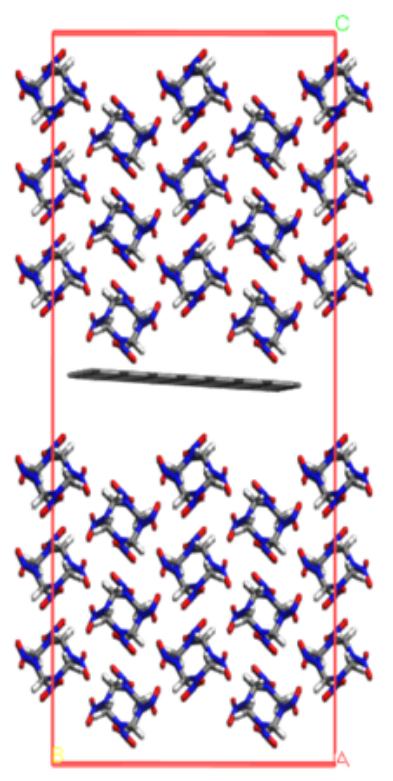

(a)

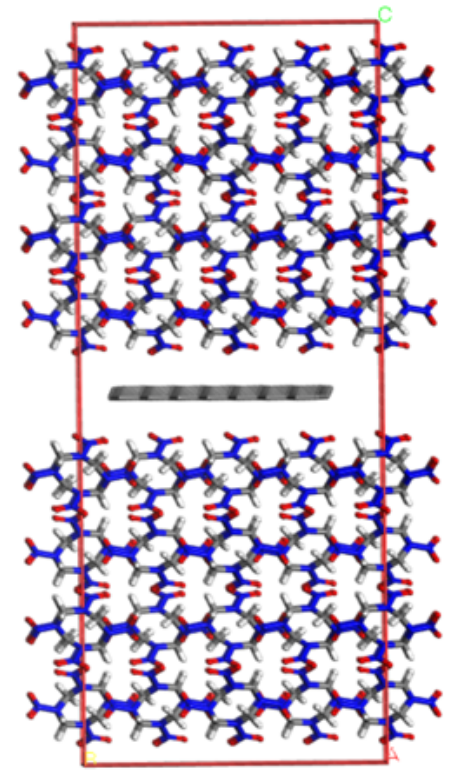

(b)

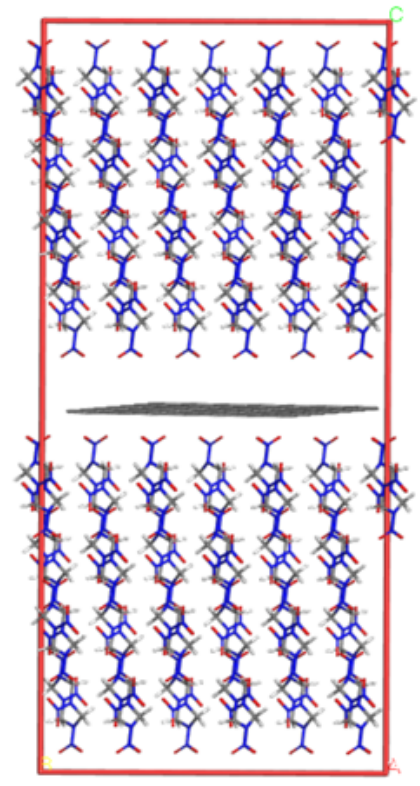

(c)

Figure 6

Models of G-001 (a), G-010 (b) and G-100 (c)in XZ plane 


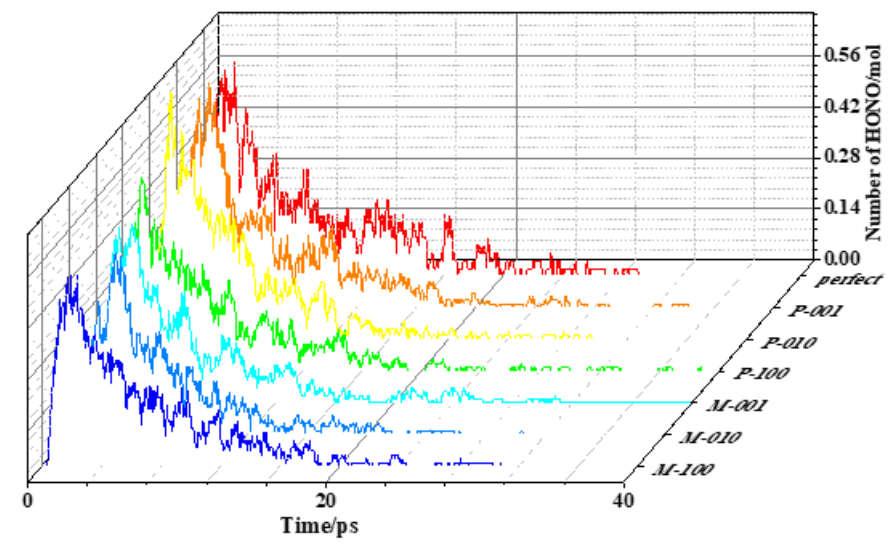

(a)HONO

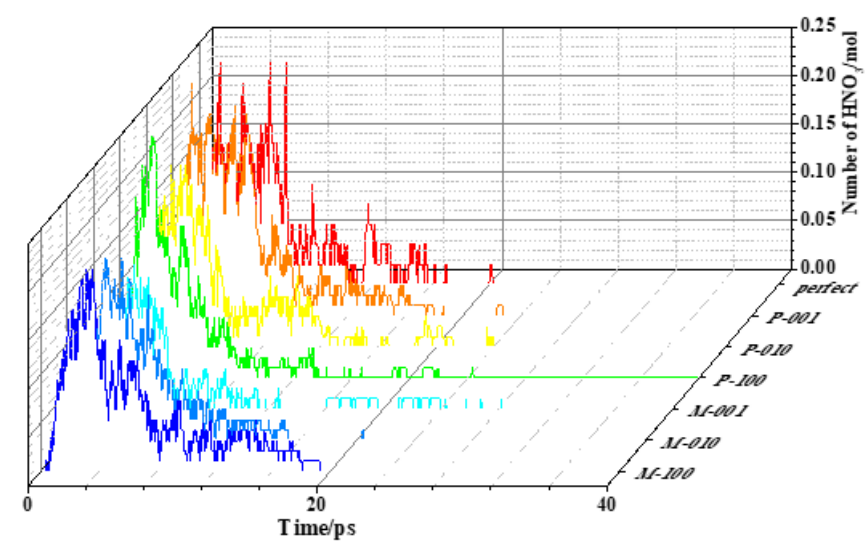

(c) $\mathrm{HNO}_{3}$

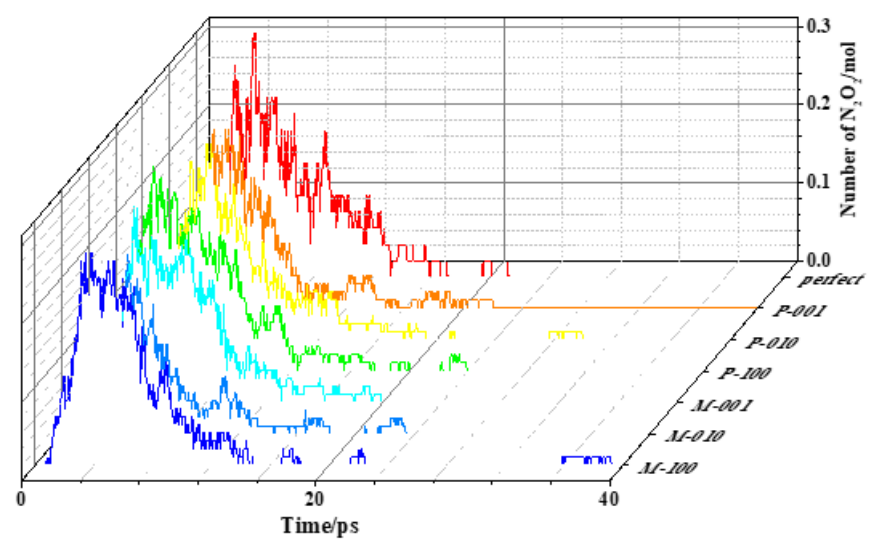

(b) $\mathrm{N}_{2} \mathrm{O}_{2}$

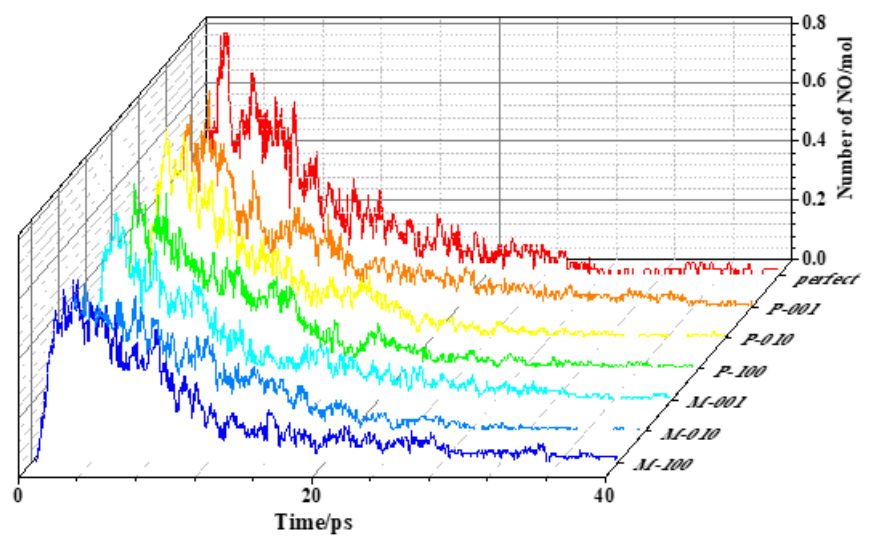

(d)NO

Figure 7

Evolution of intermediates at $3000 \mathrm{~K}$

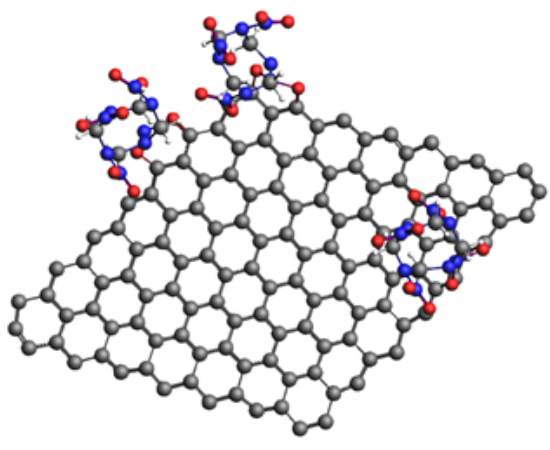

(a) M-001

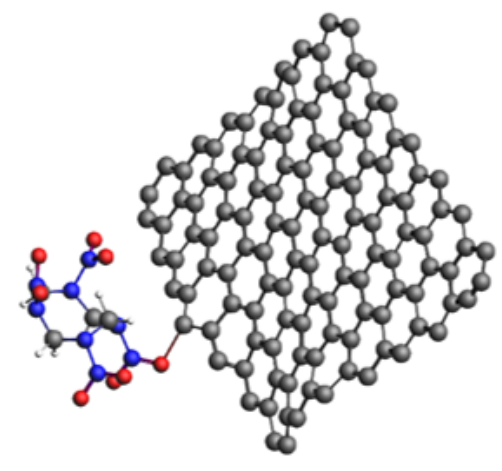

(b) $\mathrm{M}-010$

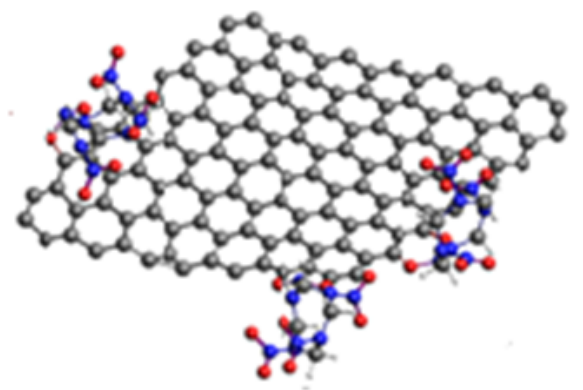

(c) $\mathrm{M}-100$

Figure 8

HMX molecules bonding on the HMX/Gr systems 


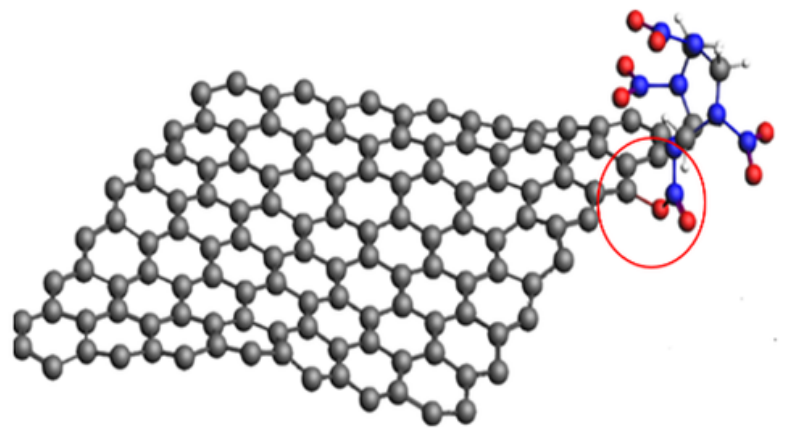

(a) $\mathrm{C}_{4} \mathrm{H}_{8} \mathrm{O}_{7} \mathrm{~N}_{8} \mathrm{O}$ (ads)

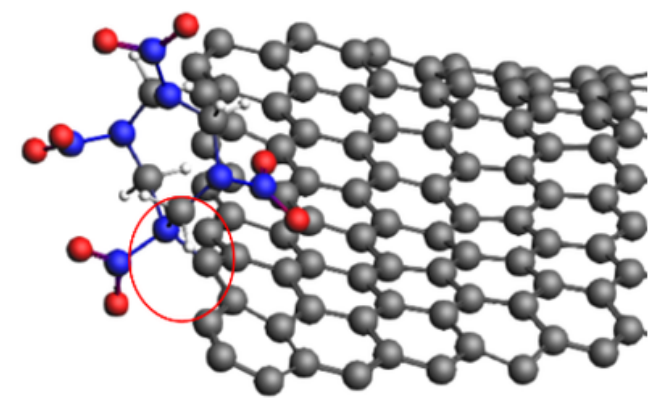

(c) $\mathrm{C}_{4} \mathrm{H}_{8} \mathrm{O}_{8} \mathrm{~N}_{7} \mathrm{~N}$ (ads)

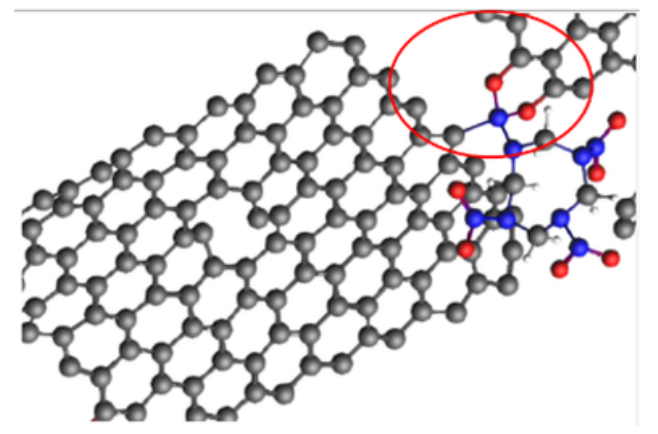

(b) $\mathrm{C}_{4} \mathrm{H}_{8} \mathrm{O}_{6} \mathrm{~N}_{7} \mathrm{~N}($ ads $) \mathrm{O}$ (ads) $)_{2}$

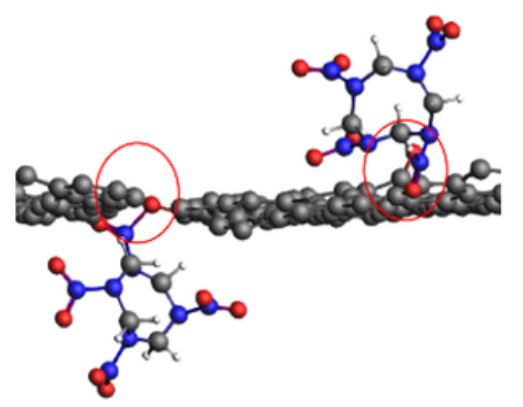

(d) $\mathrm{C}_{4} \mathrm{H}_{8} \mathrm{O}_{7} \mathrm{~N}_{8} \mathrm{O}$ (ads)

Figure 9

HMX configurations bonding on the M-001 and M-100 systems range of $1 \mathrm{GPa}$ to $31 \mathrm{GPa}$

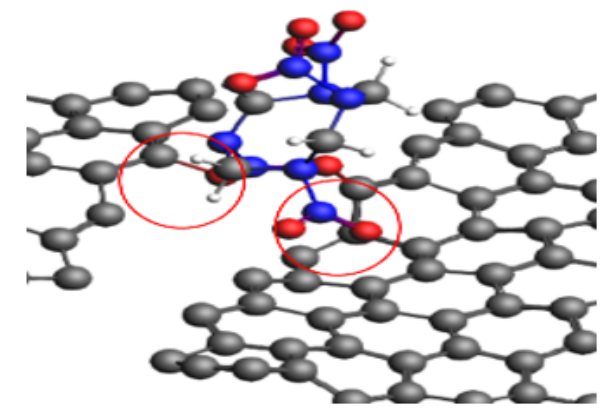

(a) $\mathrm{C}_{4} \mathrm{H}_{8} \mathrm{O}_{6} \mathrm{~N}_{8} \mathrm{O}(\text { ads })_{2}$

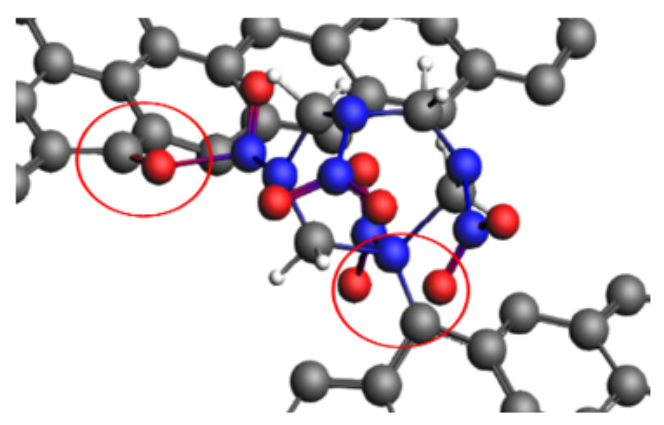

(c) $\mathrm{C}_{4} \mathrm{H}_{8} \mathrm{O}_{7} \mathrm{~N}_{7} \mathrm{~N}($ ads $) \mathrm{O}$ (ads)

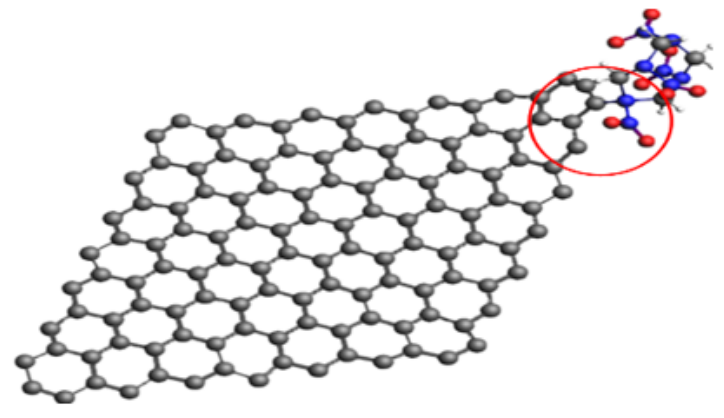

(b) $\mathrm{C}_{4} \mathrm{H}_{8} \mathrm{O}_{8} \mathrm{~N}_{7} \mathrm{~N}$ (ads)

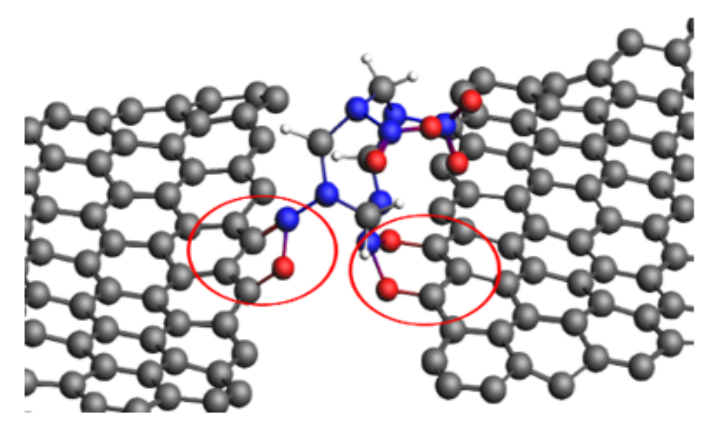

(d) $\mathrm{C}_{4} \mathrm{H}_{8} \mathrm{O}_{4} \mathrm{~N}_{8} \mathrm{O}$ (ads) 4 


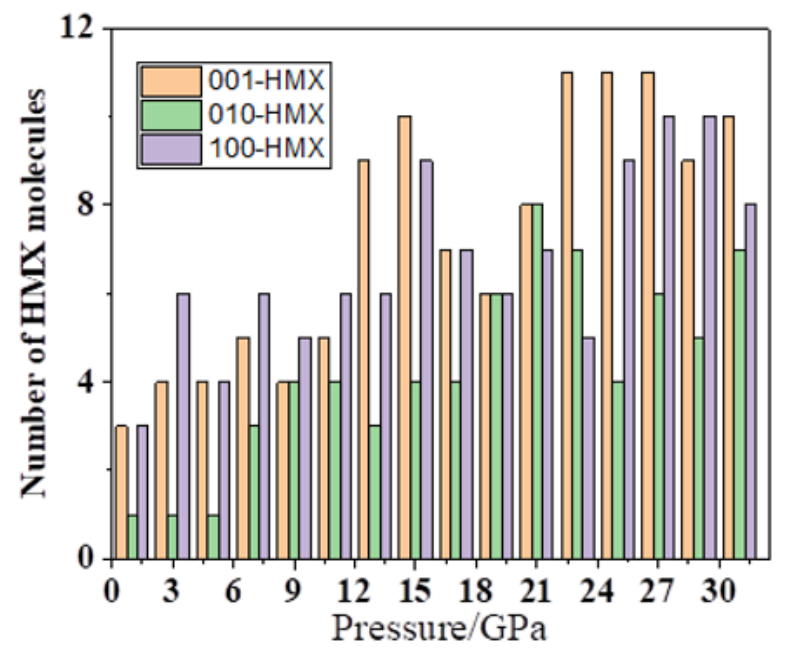

Figure 11

Number of HMX molecules bonding on the $\mathrm{Gr}$ in mixture systems from normal pressure to $31 \mathrm{GPa}$

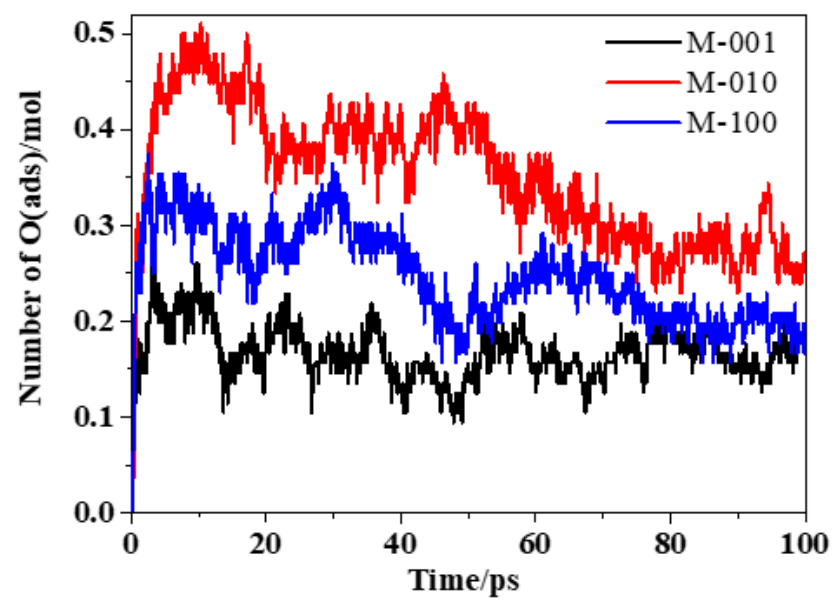

Figure 12

Evolutions of $\mathrm{O}$ (ads) in $\mathrm{HMX} / \mathrm{Gr}$ at $3000 \mathrm{~K}$ 


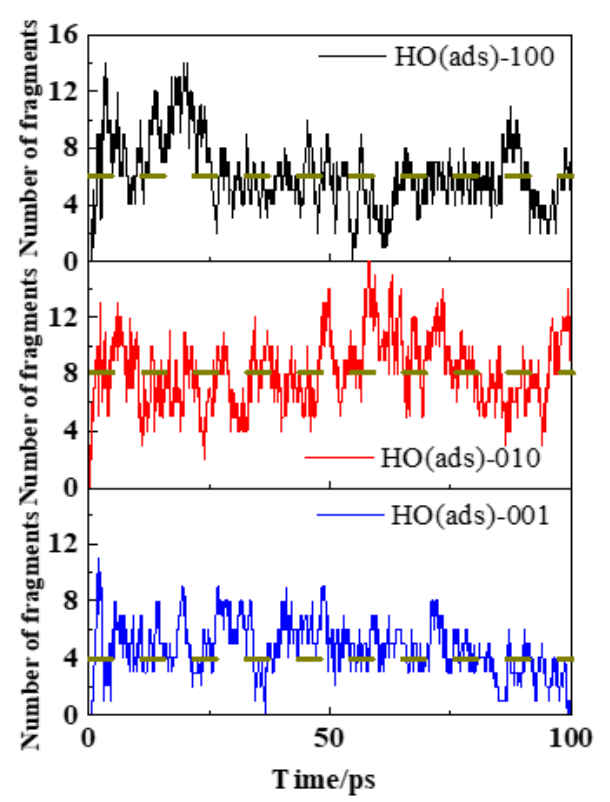

(a) HO (ads)

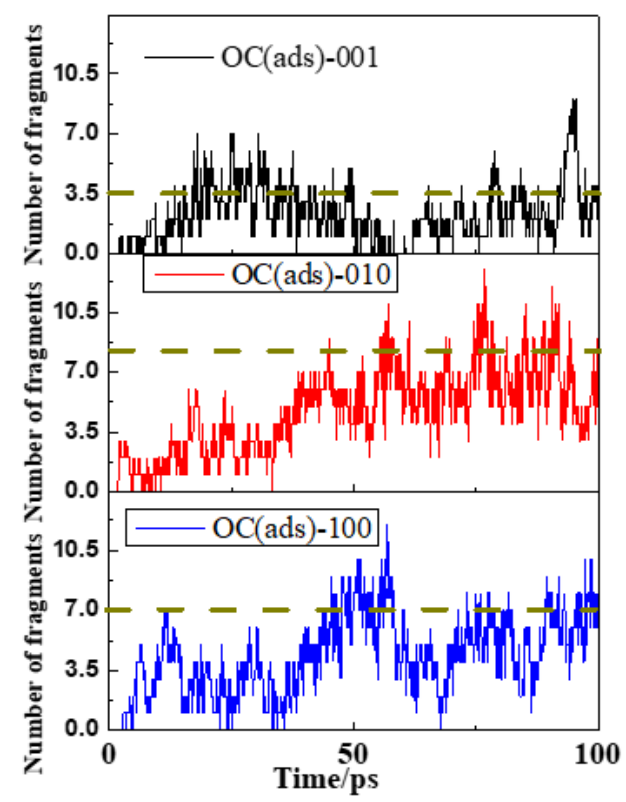

(b) OC(ads)

Figure 13

Evolutions of $\mathrm{HMX} / \mathrm{Gr} \mathrm{HO}$ (ads) and OC(ads) at $3000 \mathrm{~K}$

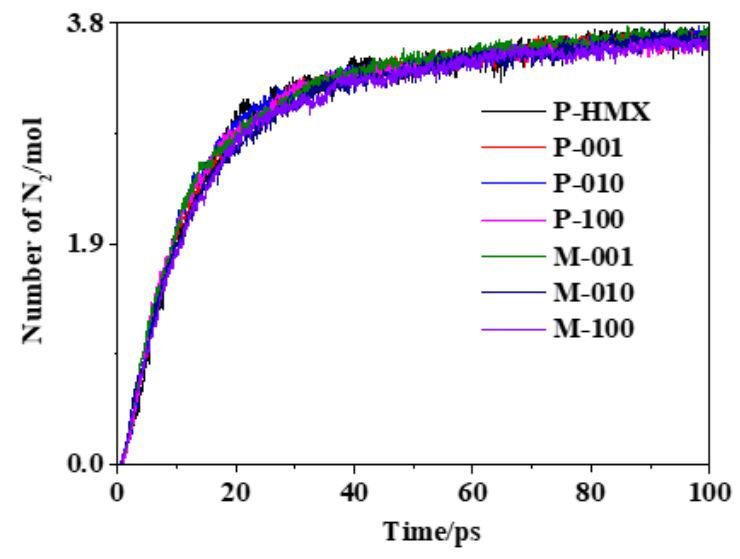

(a) $\mathrm{N}_{2}$

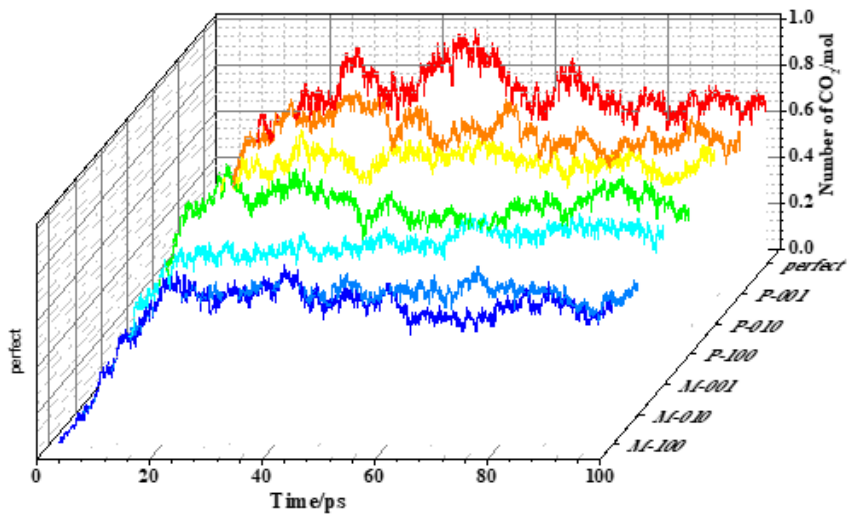

(c) $\mathrm{CO}_{2}$

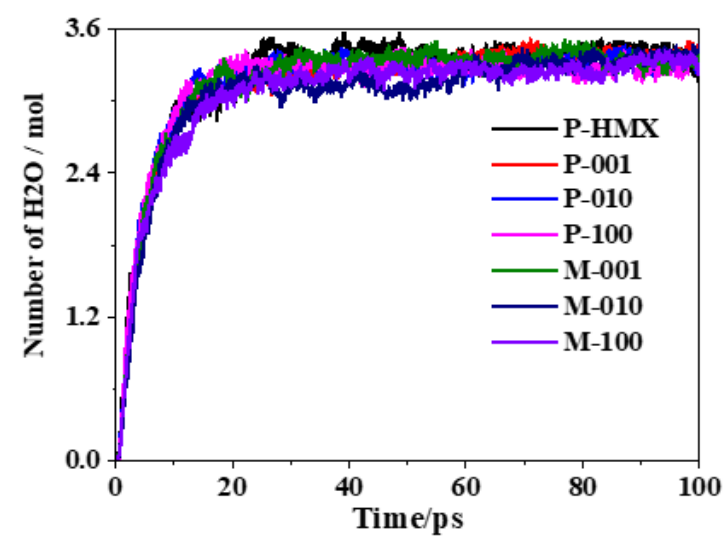

(b) $\mathrm{H}_{2} \mathrm{O}$

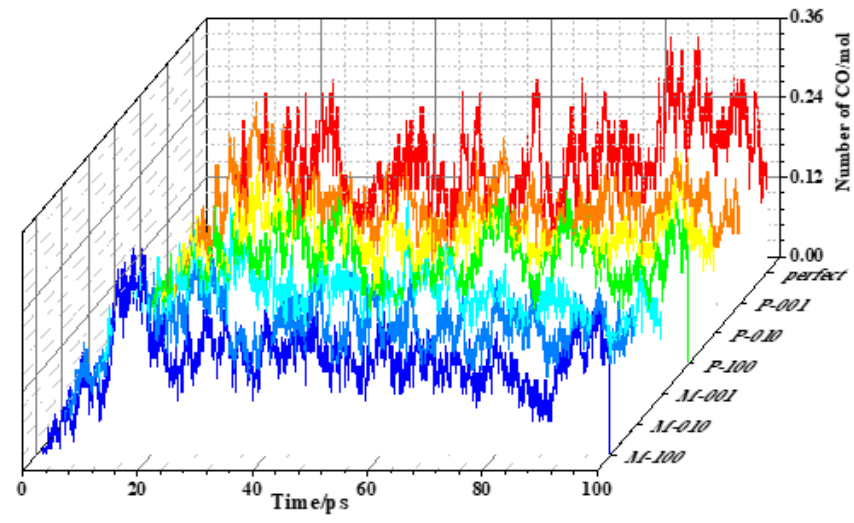

(d) $\mathrm{CO}$ 
Evolutions of $\mathrm{HMX} / \mathrm{Gr}$ final products at $3000 \mathrm{~K}$

\section{Supplementary Files}

This is a list of supplementary files associated with this preprint. Click to download.

- abstractgraphic.docx 